\title{
Unpacking the Potential of 360degree Video to Support Pre-Service Teacher Development
}

\author{
Nicoletta Balzaretti ${ }^{\mathrm{a}}$, Andrea Ciani ${ }^{\mathrm{b}}$, Chelsea Cutting ${ }^{\mathrm{c}}$, Lisa O'Keeffe ${ }^{\mathrm{d}}$, Bruce Whi- \\ te $^{\mathrm{e}}$ \\ ${ }^{a}$ University of Bologna, Italy, nicoletta.balzaretti@unibo.it,0000-0001-8440-8473 \\ ${ }^{b}$ University of Bologna, Italy, andrea.ciani5@unibo.it,0000-0003-4703-7890 \\ ${ }^{c}$ University of South Australia, Australia, Chelsea.Cutting@unisa.edu.au, 0000-0002-3497-9865 \\ ${ }^{d}$ University of South Australia, Australia, Lisa.OKeeffe@unisa.edu.au, 0000-0002-3728-2182 \\ ${ }^{e}$ University of South Australia, Australia, Bruce.White@unisa.edu.au, 0000-0002-6716-1656
}

\begin{abstract}
Video has become a useful tool in Initial Teacher Education for self-evaluation and reflection by pre-service teachers (PSTs). The availability of 360degree video cameras and web-based applications, to review and annotate $360 d e g r e e$ videos, allows PSTs greater flexibility to view and review their practice from a variety of perspectives. This study explores PSTs' use of 360degree video for reflection on their teaching practice. 360degree video provides PSTs with the capacity to pan 'around' the video, and in doing so has supported PSTs to detach and reflect on their own practice. The findings suggest that the PSTs valued the additional perspectives afforded by the 360degree nature of the video, which had a particular impact on their understanding of their presence, interactions and explanations. Peer video viewing was also found to be a useful tool in supporting PSTs to 'notice' additional areas for improvement in their own practice.
\end{abstract}

Keywords: initial teacher education, reflection, audio-visual equipment

\section{Introduction}

The research fields of Education and Technology have become more aligned in recent decades. In particular, common areas of research include the development of sophisticated technological instruments and tools for education and studies in pedagogical and psychological fields that are intended to demonstrate what and how student learning from pre to high school can be enhanced. The use of video by teachers to document and analyse their own practice has been supported since 1973 (Fuller \& Manning, 1973). Video can be useful as a sort of psychotherapeutic 'self-confrontation' in professional practice, for the purpose of increasing the accuracy of pre-service teachers' self-perceptions and their openness to feedback (Fuller \& Manning, 1973; Recesso \& Zepeda, 2008). Specifically, in pre-service teacher (PST) training, classroom videos can be a powerful means to promote the PSTs' noticing of classroom management and interactions. Research, such as Gross and Han (2004) and van Es and Sherin (2002) suggest that the systematic use of videos with PSTs over time can help them shift away from simply observing or describing their own practice to focusing more on interpreting observed events.

Recesso and Zepeda (2008) identify some of the limitations of using video recording in education. These include technical issues, and of most relevance to this study, inadequate capture of the entirety of the classroom. In particular, they raise concerns about the capacity of mounted video cameras to adequately capture an entire interaction. One of the challenges with using standard video recording equipment in classroom situations is that decisions need to be made about where to point the camera. Such decisions create a researcher or teacher bias in that it requires the researcher/teacher to predetermine what might be worth recording (Clarke, 2006). One solution to this is using multiple cameras so that lessons can be recorded from multiple perspectives. Another is the use of 360 degree cameras. This project incorporates 360-degree video recording, which are video recordings from an immersive 360-degree perspective. This paper presents a summary overview of the initial exploration of the use of 360 degree video recordings with a cohort of PSTs at University of South Australia. This paper explores the affordances of 360 degree video in regard to the learning 
processes it might foster and develop. This research is guided by the question 'How can 360degree video enable deep reflection of preservice teacher's awareness of their presence?'

The use of video in PST education is widely acknowledged as being effective in promoting and supporting teacher change (Guskey, 1986; Richardson \& Placier, 2002) and teacher professionalism. Video analysis literature illustrates a large variety of purposes for using video in teacher learning. These include lesson analysis (Santagata, 2014), scaffolding teachers' professional development (Brophy, 2004; Sherin, 2004), promoting discussion between teachers (Borko et al., 2008) and building learning communities (Sherin, 2004; van Es, 2012). In all these cases, video becomes an effective tool for decentralizing oneself, removing action from 'here and now' and slowing the emotional burden on the reviewer and triggering systematic processes of thoughtful thinking. Rich and Hannafin's (2009) use of video for PST reflection also noted the usefulness of video in supporting PST reflection. In particular, they identified how PSTs using video reflection were more likely to notice the ways in which students were involved (or not) in their lesson and how they approached these students. They suggest that supporting PSTs to review their own practice using video enables them to 'step back' from the cognitive overload of 'in-the moment' decision-making in practice and to become more analytical about what was going on (Rich \& Hannafin, 2009). This 'stepping back' facilitated realisations about the discrepancies between their recalled experiences and what they observed on the video. This is akin to what Sherin and van Es (2005) term 'noticing'. Similarly, recent work at the University of Bologna highlights how video analysis technologies are a powerful means to activate teachers' professional learning to create awareness, understanding and application of the role that formative assessment plays in mathematics teaching and learning (Ferretti, Michael-Chrysanthou \& Vannini, 2018). Ferretti et al. (2018) and Balzaretti et al. (2018) suggest that there are four key phases in the use of video for reflection, which are:

- Noticing and describing,

- Looking for cause-effect links,

- Exercising analytical thinking,

- Identifying possible alternatives to those observed.

They also suggest that going through the 'video noticing phase' is key in moving from video viewing to a deep reflection. The effectiveness of these different phases is linked to the consistent and intentional use of tools to support PST reflection.

Noticing can be defined as the ability to attend to what is significant in a complex situation also referred to as highlighting (Goodwin, 1994) and marking (van Es \& Sherin, 2010). Because of the multitude of things happening at any one time in a real classroom, PSTs need to make choices about where to direct their attention and what events to pursue at any given moment. Noticing also involves the ability to make connections between specific events and the broader principles they represent (Hughes et al., 2000) and using knowledge of one's context to reason about noteworthy events. In 2001, Sherin and van Es introduced the notion of video annotation to facilitate teacher reflection and improve their 'noticing' skills, using Video Analysis Support Tool (VAST). They found that using video annotation helped teachers to 'notice' more in their classrooms (Sherin \& van Es, 2005), this resulted in changes such as focusing more on student thinking and becoming better at identifying significant interactions in their lessons. They also note that teacher annotations typically start as descriptions of events in their classrooms, over time these annotations moved from an evaluative stance, considering whether what they'd done in the lesson had 'worked', to an interpretive stance consisting of detailed explanations of the teaching strategies used.

This early research on the use of video for self-review demonstrates that structured or focused reflection is most effective in facilitating the development of both PSTs and in-service teachers. Based on this early literature, we know that those who engage in video-based reflection, using a focused approach, can expect to: (a) confront discrepancies between their perceived and actual performance and consequently increase the accuracy of their self-perception (Fuller \& Manning 1973); (b) step back from the cognitive overload of in-the-moment analyses of reflections (Rich \& Hannafin 2009); (c) increase their ability to notice significant interactions in the classrooms, and (d) shift their focus from their own actions (pedagogy) to their students' thinking (Sherin \& van Es, 2005). However, Barth-Cohen, Little \& Abrahamson (2018, p. 85) acknowledge that "little is known about what can be achieved with PSTs who are just beginning to make sense of student learning'. They too suggest that an ability to identify and notice key moments of teaching/learning are of particular importance.

Despite an increased focus on teacher noticing in recent years, little is known about the development of teachers' ability to notice and how to effectively support this development (van Es \& Sherin, 2010). The use of artefacts of practice, such as video or student work, may support PSTs in their observations and sense-making of different teaching practices. Key points to consider are firstly in designing video-based activities, it is fundamental to clarify which learning goals are being pursued (Sherin, 2007). Then, an activity, aligned with these goals, should be designed. In this regard, it seems important that video must be conceptualised as a technological tool and systematically embedded by appropriate instructional strategies. Expertise in noticing involves attending selectively to notable classroom events, and interpreting or reasoning about the events based on one's knowledge of the context (Sherin, 2007). The video viewing process and the 'noticing' process are different phases and as such have different progressive foci (van Es \& Sherin, 2010). PSTs need to be guided and supported to build their reflexive thinking so that they can move through these phases. Only then can they be expected to connect observed practices with their own teaching practice. This kind of deep reflection can be developed in two steps: 
- comparing video practices with one's own teaching practices (even if they are a simulation during university lessons);

- re-thinking the teaching practices within a theoretical framework.

\section{Methods}

This study involved a cohort of PSTs undertaking a curriculum course in Mathematics Education as part of their Master of Teaching (Secondary). PSTs are in the first study period of the first year of their program and in general have no formal teaching experience. Of the class of 33 PSTs, a total of 28 volunteered to participate in our study. As part of the assessment in this course the PSTs, in assigned groups, prepare and give a teaching presentation (recorded using a 360degree camera) for their peers on an aspect of mathematics. This presentation is their first formal attempt at teaching mathematics and follows a number of workshops focused on pedagogical approaches to mathematics. Due to time constraints, the students were only able to complete one formal presentation and reflection sequence. Following their presentation, the group engaged in dialogic feedback with their tutor and their peers before submitting a group written reflection, which was also assessed. For this project, the video files were shared with the PSTs after they had completed their group reflection. The PSTs then reviewed and annotated their videos and completed an additional reflection using a web-based survey, which included some questions related to their use of the 360 degree video and a summary comment on what they noticed about their presence, interactions and explanations. The PST annotations, the survey responses and the case studies described below were used to examine the key research question guiding this phase of our work is How can 360degree video enable deep reflection of pre-service teacher's awareness of their classroom presence?

Two participant (Pseudonyms used) case studies have been compiled from the survey and annotation data. These participants were selected based on the level of detail they included in their video annotations. The video data for each of the case study participants has been independently coded and recoded by three of the research team against three criteria. These criteria were chosen as relevant to their early stage of teacher training and are their presence, their interactions and their explanations/board work. Each of the three researchers reviewed the PST videos and created a detailed feedback summary. The three independent summaries were then collectively reviewed for similarities and differences, before a combined summary was agreed upon. These final summaries are referred to, later in this paper, as the experienced teacher reflection (ETR). This was used in conjunction with the PST annotations to create the case studies presented.

The 360degree web-based application used in this project was created as part of an Australian Tertiary Network project (O'Halloran et al., 2017). The web-based application is designed for viewing, annotating and analysing 360degree video. It was designed to enable PSTs to pan the screen around to access to full 360 degree view of the recording and explore their videos from different perspectives. The software enables users to attach annotations directly to the video that are visible to others. While there are other 360degree hosting platforms available, this application was selected for this project as it was designed for purpose and allows greater control over the privacy and sharing of the video files. Each group had access to their own group videos only.

\section{Overview of PST reflection}

One of the survey open-ended questions was concerned with students' feedback in terms of what they learned while viewing the video. The specific question for the students was 'How did watching your sub-groups video help you?'. Using NVIVO11 as a qualitative analysis tool, there were a total of 966 words coded. From this analysis, the following words were identified as co-occurring: watching/video presentation/lesson and improved/helped my teaching (34 instances). In addition, in the PST's reflections, the semantic frequencies have been coded and summarised and are presented in Table 1 below.

Table 1. Overview on PST reflections on using a 360degree video recordings

\begin{tabular}{lll}
\hline Focus of PST's reflections & Frequencies $(\mathrm{N}(=26)$ & Examples \\
\hline Body language and gestures 6 & $\begin{array}{l}\text { Watching how they present the information with the various tone of } \\
\text { voice and hand gestures is something I really need to improve on. } \\
\text { (A.K.) }\end{array}$ \\
$\begin{array}{l}\text { I was very interesting to what your own body language and stance. I } \\
\text { realised that I use the word ummm a lot and need to be more confi- } \\
\text { dent in what I am saying. }(\mathrm{E} .)\end{array}$
\end{tabular}


How comparison with others can affect one's own perception

General learning from using the 360 degree videos

The use of 360 degree videos to improve one's own teaching practice

Technical limitations of 360degree videos

\begin{abstract}
The comparison video of another classroom helped me with my understanding of how to present the given resources differently, such as why there were different concentrations, explanations. (S.S.) Watching sub-group video helped me in understanding how the same content can be presented differently. The part I did and the same section the other member introduced in another class, the content was same, but the way of presentation was different. It gave good learning.
\end{abstract} (J.P.)

5

It's not easy to watch yourself, but I definitely feel as though I learned something about how I present myself in the classroom as a result. (C.E.)

It gives me a perspective from audiences. So I can give myself some suggestion objectively and make it better next time. (B.J)"

8

I could also see areas of improvement that I could also improve on as well in regards to teaching pedagogies. (N.S.)

It showed me their different style of doing certain activities, which normally I would do in some other way and hence giving me a wider perspective of how else I could do it. (A.K)

4

This is to reflect myself about all my presentation and how we can improve in the future. If the volume was good, I guess it will help more for evaluation and achievement. (S.L.)

If the 360 was roaming instead of stationary would have helped to gain insight into how effective the demonstrations/examples were. (J.C.)

From a normative perspective, what one is trying to improve is their understanding of 'what to do' in the classroom (Fuller \& Manning, 1973; Lampert \& Ball, 1998). The PST reflections primarily focused on body language, verbal language and gestures, which is consistent with the first dimension of the noticing phase. Even though some of the students wrote about the difficulty in watching themselves, they also identified that they believed they learned something as a result of the video viewing and noticing. They indicated that the videos provided them with an opportunity to watch themselves from a detached perspective. A particular focus on classroom communication also emerged from the students' annotation, the two key points raised by the PSTs were the importance of clarity and the use of explanation.

From a developmentalist perspective, one objective in using a 360degree camera is to build knowledge on "how to interpret and reflect on classroom practices" (Sherin, 2004, p. 14). Data indicate that some students found the $360 \mathrm{dgeree}$ video useful for improving their ability to detach and reflect on their own practice. In particular, they made reference to the affordances of comparison with peer video with the explicit goal to improve one's own practice. The PSTs noted both strengths and limitations from using the 360degree camera for their learning. They underlined how the 360degree nature of the videos enabled them to watch their own video 'from an audience point of view', which was helpful for them to understand their teaching interactions and thus improve their teaching skills.

\section{Two Participant Case studies (Students at University of South Australia)}

In the survey of the two participant case studies presented below, each of the case study participants indicated that they found 360 degree video recording and annotations moderately (1) to very (2) useful.

\section{Case Study 1: Claire, a PST with mathematics as her major area of study}

Presence: The ETR of Claire's video suggests that she initially begins this presentation with a very poor presence, she comes across as rigid, unsure what to do with her hands and seems to be aimlessly wandering during the early stages. However, over time she seems to be more relaxed. Claire's initial comment on her video is to offer positive reinforcement to her partner and suggested that his energy was a bit low, he could show more enthusiasm. She then goes on to identify how all of their body language needs improvement and how she herself also needs to have more energy when talking to maintain student focus and attention. She does note the change in this towards the end of the workshop. This change was noted in the ETR also, while her position and presence became more relaxed towards the end of the workshop this seems to align with when she is explaining content. She seems to be more comfortable in explaining aspects of content to the whole group than interacting at a meaningful level with small groups. In regard to her presence, Claire is aware that her body language needs to be improved, her speaking needs to be louder, more energetic and a bit slower. Claire summarised her reflection by saying, it's not easy to watch yourself, but I definitely feel as though I learned something about how I present myself in the classroom as a result.

Interactions: The ETR suggest that Claire often wanders around the groups without really connecting with the groups to ask any meaningful questions. She also needs to speak out a little more and be a bit more assertive when joining a group to engage in discussion. Her movement around the class to work with different groups is limited to one or two groups - possibly as these are peers she is more comfortable with. Hence, she doesn't notice those disengaged/quiet and does not interact with every student. When she is working with groups, she often restates the task in the same way several times and she has a tendency to want to DO the task for the participants rather than probe or challenge their understanding. For example, she manipulates the materials for first group (effectively solving the problem for them) in- 
stead of questioning them about what they have and what they are thinking. Claire, included little detail on her interaction with peers in her reflection. She suggested it was difficult to get every group interaction on the video because the group at that table blocked the view of others. And while this is somewhat true, it is still very easy to see who Claire interacts with and what this interaction entails (not possible to hear at all times).

Explanations: Claire is also more focused on the actual content rather than the teaching method (which was the purpose of the presentation). Claire was not aware of this in her post-presentation debrief. However, after watching the video, she now seems to be aware of her tendency to focus on 'telling' participants what the content is, rather than explaining the methods behind it (which is the focus of the presentation), here I should be explaining why I have them up the front and what the students would be gaining from this activity. Claire also indicates that her explanations are all clear but often could have used more 'padding'. However, the ETR identified that many of her explanations are quite long and could be much more succinct.

In the video, Claire is clearly aware of losing her participants attention but does not seem to be aware of her own role in this lack of engagement. This lack of engagement occurs when she is talking 'at them' more so than engaging them in her discussion. Her response to this is to assume they do not understand and restate her explanation rather which does not help. Claire does not refer to this in her reflection, which emphasises her lack of understanding about her role and about the potential impact of her body language.

\section{Case Study 2: Beth, a PST with a mathematics as her minor area of study}

Presence: The ETR of Beth's video identified that Beth needs to work on her presence. She came across as standoff-ish when her teaching partner was speaking and in general looked very passive and unsure at the start of this presentation. She located herself at the computer to press for the next slide, which did not help with her lack of presence. When introducing her first task, she seemed unsure about the focus/purpose of the task and didn't connect this with her teaching approaches. Beth's initial comment on the video was a negative realisation about how much standing around at the top of the room herself and her group did. The summary point Beth provided was that her group stood in one spot, [we] definitely needed to walk around the classroom more and use enthusiasm both verbally and non-verbally. Of additional note here is that she uses the term 'walk around' rather than work with or engage with participants.

Interactions: Beth's movement around the group seemed unintentional. While she does move around the room and interact in some group tasks, she regularly wandered away from a group without any interaction or with only superficial interaction - no questioning. Beth spent most of her interacting time with the same group or she went to a group that a partner teacher was already at. This meant that she didn't notice opportunities to connect and engage with other participants. When she did work with a group, she often crouched to get down to the groups level, but she needs to ask more questions rather than just 'tell' then what to do/how to solve the problem. Beth's reflection does not concentrate much on interactions (only comment was: could have been more interactive) as the issues in regard presence and explanations take priority for her, suggesting a lack of understanding of what 'interacting' means.

Explanations: Beth did not use tone well and hence the ETR indicated that it was difficult to distinguish when what she was saying was an explanation, an instruction or an initiation of action. This did not appear in her reflection but she needs to be much more aware of her need to signal through expression, particularly when starting an activity. The ETR identified that Beth's explanations need to be much clearer and more direct, she also needs to allow time between getting participant attention and starting with instructions to ensure she has everyone's attention. While Beth used participant recordings on their mini whiteboards in an attempt to take some feedback on their level of understanding, she did not use this as a teaching point so missed opportunities to expand on and share participants thinking. Beth indicated a great awareness, in her video reflection (in comparison to her post-presentation debrief), of the issues with her and her group's explanations, based on how unclear participants were about what they were asked to do. She identified where they needed to have pre-prepared examples, and that they had not factored in the level of knowledge and understanding of their participants (i.e., University Students) into the planning of time for activity duration. She also noted a limitation in regard to their planning for this presentation, in that her group need[ed] to minimise talking time, get the group involved, ensure that we are able to help Michelle (one of her teaching team) out by having a better understanding of the task. If we were to do this again we definitely know where to improve. We should have incorporated more resources for the pre-service teacher to use. Beth clearly used the 360degree nature of the video to reflect on how participants were engaging with the task, and she was aware of the tendency of participants to go off topic and off task at particular points. In summary, Beth acknowledged that her group needed more visual aids [and] more demonstrations.

These initial case studies highlight that these PSTs tended to focus primarily on themselves as individuals delivering content. They rarely focused on interpreting the interaction they had with students and/or the effect their pedagogy had on the engagement between students. This suggests that these PSTs are primarily in the first phase of video noticing, which is to be expected given the PSTs participating in this study were very early in their initial teacher education program. However, the PSTs did provide some comments about the affordances of the 360degree in supporting them to see their teaching from the perspective of their own students/participants. This suggests that they are beginning to develop analytical thinking with regards to their teaching practice - a key step towards deep reflection. 


\section{Summary and Conclusions}

The study aims to provide an overview of the potential of 360degree videos to support PSTs learning through deep reflection. The use of 360 degree video recording in this project provides PSTs with the capacity to pan 'around' the video and thus enables them to have a greater understanding of what is happening around them as they teach. As discussed, there are potential innovations in the research methods outlined, in particular in analysing video annotation and reflection data for insight into students' sharing and co-creation of meaning. The affordance of using $360 \mathrm{degree}$ video analysis technologies in learning design appears to have great potential. Collaborative viewing and annotation of group presentations/teaching via 360degree video technologies provide a powerful new platform from which to construct and co-create meaning about their teaching and learning. Scaffolding PSTs, with 360degree video reflection, can support them to develop well-structured video noticing skills and hence could be an effective tool to extend naive video viewing (especially for PSTs) towards deeper reflection.

It is important to note that this initial work is only early-stage explorations of the potential of 360degree video. Further works need to be done on how this can inform PSTs' future teacher. It is also highly likely that further collaborations between University of South Australia and University of Bologna may generate a suitable tool(s) that may support to interpret proximities of coherence and cognition derived from PSTs learning experiences.

\section{References}

Balzaretti, N., Leonard, S.N., Lim, L., Unsworth, P. \& Vannini, I. (2018). Innovating methodology through international collaboration: Expanding the use of video analysis for understanding learning designs. Italian Journal of Educational Research. 11 (21), 11-30.

Barth-Cohen, L.A., Little, A. J. \& Abrahamson, D. (2018). Building Reflective Practices in a Pre-service Math and Science Teacher Education Course That Focuses on Qualitative Video Analysis. Journal of Science Teacher Education, 29(2), pp.83-101.

Borko, H., Jacobs, J., Eiteljorg, E., \& Pittman, M. E. (2008). Video as a tool for fostering productive discussions in mathematics professional development. Teaching and Teacher Education, 24(2), 417-436.

Brophy, J. E. (2004). Using video in teacher education. Amsterdam: Elsevier.

van Es, E. A. (2012). Examining the Development of a Teacher Learning Community: The Case of a Video Club. Teaching and Teacher Education: An International Journal of Research and Studies, 28(2), 182-192.

van Es, E. A. \& Sherin, M. G. (2002). Learning to notice: scaffolding new teachers' interpretations of classroom interactions. Journal of Technology and Teacher Education, 10(4), 571-596.

van Es, E.A. \& Sherin, M.G. (2010). The influence of video clubs on teachers' thinking and practice. Journal Math Teacher Education, 13, 155-176.

Ferretti, F., Michael- Chrysanthou, P. \& Vannini, I. (Eds.) (2018). Formative assessment for mathematics teaching and learning: Teacher professional development research by videoanalysis methodologies. Milano: FrancoAngeli.

Fuller, F. F. \& Manning, B. A. (1973). Self-confrontation reviewed: a conceptualization for video playback in teacher education. Review of Educational Research, 43(4), 469-528.

Goodwin, C. (1994). Professional vision. American Anthropologist, 96(3), 606-633.

Guskey, T. R. (1986). Staff Development and the Process of Teacher Change. Educational Researcher, 15(5), 5-12.

Hughes, J. E., Kerr, S. P. \& Ooms, A. (2005). Content-focused technology inquiry groups: cases of teacher learning and technology integration. Journal of Educational Computing Research, 32(4), 367-379.

Lampert, M. \& Ball, D. L. (1998). Teaching, multimedia, and mathematics: Investigations of real practice. New York: Teachers College Press.

O’Halloran, K., Tan, S., Sheffield, R., Mallet, D., Aubusson, P., Berry, A. \& O'Keeffe, L. (2018). Encouraging and mapping student engagement through 360-degree video annotation and data analytics. Final Report, Curtin University, Australia.

Recesso, A.M. \& Zepeda, S.J. (2008). Evidential reasoning and decision support in assessment of teacher practice. In T.J. Kowalski \& T.J. Lasley (Eds). Handbook on data-based decision making in education (pp.363-381). Abingdon: Routledge

Rich, P.J. \& Hannafin, M. (2009), Video annotation tools: Technologies to scaffold, structure, and transform teacher reflection. Journal of Teacher Education, 60(1), 52-67.

Richardson, V. \& Placier, P. (2002). Teacher Change. In V. Richardson. Handbook of Research on Teaching (pp. 905947). Washington DC: American Educational Research Association.

Santagata, R. (2014). Video and teacher learning: key questions, tool and assessment guiding research and practice. Beitraege zur Lehrerbildung, 32(2),196-209.

Sherin, M.G. \& van Es, E.A. (2005). Using video to support teachers' ability to notice classroom interactions. Journal of technology and teacher education, 13(3), 475-491.

Sherin, M.G., \& Han, S. Y. (2004). Teacher learning in the context of a video club. Teaching and Teacher Education, 20(2), 163-183. 
Sherin, M.G. (2004). New perspectives on the role of video in teacher education. In J. Brophy (Ed.), Using video in teacher education (pp. 1-28). Oxford, UK: Elsevier.

Sherin, M.G. (2007). The development of teachers' professional vision in video clubs. In R. Goldman, R. Pea, B. Barron, \& S. J. Derry (Eds.), Video research in the learning sciences (pp. 383-395). Mahwah, NJ: Lawrence Erlbaum.

Sherin, M.G., \& van Es, E.A. (2005). Using video to support teachers' ability to notice classroom interactions. Journal of Technology and Teacher Education, 13(3), 475-491. 